Provided for non-commercial research and education use. Not for reproduction, distribution or commercial use.

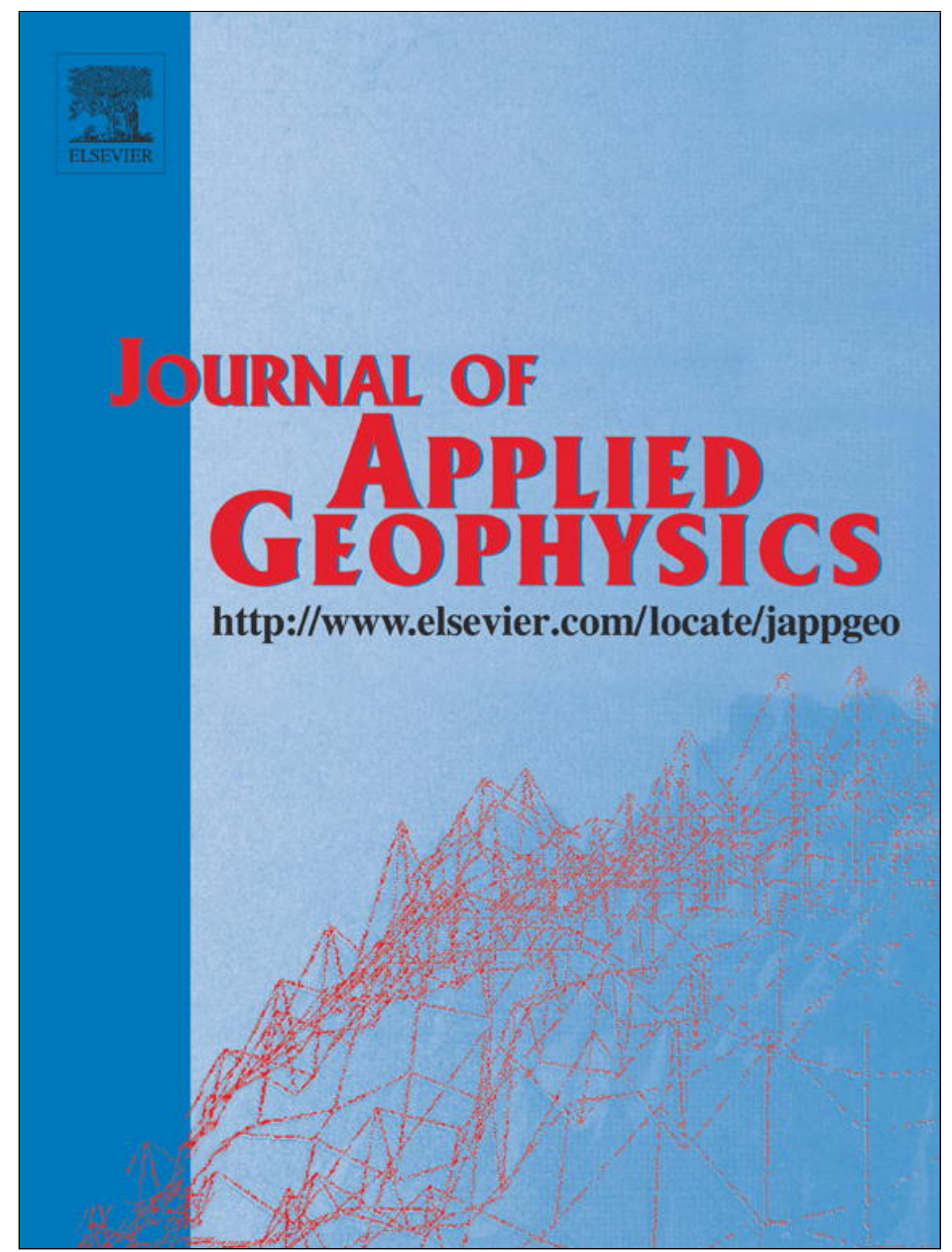

(This is a sample cover image for this issue. The actual cover is not yet available at this time.)

This article appeared in a journal published by Elsevier. The attached copy is furnished to the author for internal non-commercial research and education use, including for instruction at the authors institution and sharing with colleagues.

Other uses, including reproduction and distribution, or selling or licensing copies, or posting to personal, institutional or third party websites are prohibited.

In most cases authors are permitted to post their version of the article (e.g. in Word or Tex form) to their personal website or institutional repository. Authors requiring further information regarding Elsevier's archiving and manuscript policies are encouraged to visit:

http://www.elsevier.com/copyright 


\title{
Some tests of 3D ultrasonic traveltime tomography on the Eleonora d'Aragona statue (F. Laurana, 1468)
}

\author{
P. Capizzi *, P.L. Cosentino, S. Schiavone \\ DiSTeM Department, University of Palermo, via Archirafi 26 Palermo, Italy
}

\section{A R T I C L E I N F O}

\section{Article history:}

Received 6 July 2012

Accepted 28 January 2013

Available online 14 February 2013

\section{Keywords:}

Ultrasonic measurements

3D tomography

Inversion tests

Lateral resolution

Voxel size

Raytracing

\begin{abstract}
A B S T R A C T
The use of a non-destructive technique in situ can be a valuable diagnostic tool to support verification of restoration, as well as a monitoring technique in works of art or historical monuments.

We present a high resolution 3D ultrasonic tomography to one of the most important statues of the Regional Gallery of Palazzo Abatellis of Palermo, the bust of Eleonora d'Aragona by F. Laurana (1430-1502). This technique allowed to study the structural continuity of the material of the marble.

Some tests have been carried out to optimize inversion parameters, such as voxel size and to choose between straight and curved rays.

We propose to calculate a minimum lateral resolution using the sampling frequency instead of that of the probes. Consequently it was chosen to use a voxel size of $2 \mathrm{~cm}$, lower than the expected resolution, $0.07 \mathrm{~m}$ (calculated considering the median ray length), and also to use curved rays instead of straight rays approximation.

The resulting model showed velocity values corresponding to a sufficiently homogeneous and well-preserved marble, but in the lower front portion of the trunk at the breasts, that bears the entire weight of the artwork, low velocity values are present.
\end{abstract}

(C) 2013 Published by Elsevier B.V.

\section{Contents}

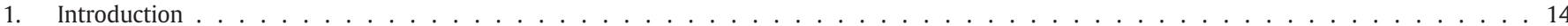

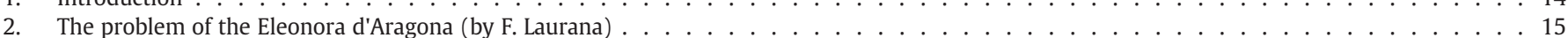

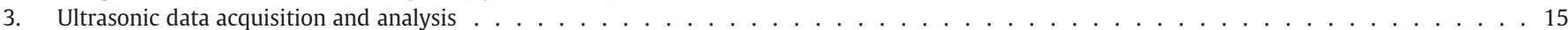

4. Inversion tests . . . . . . . . . . . . . . . . . . . . . . . . . . . . . . . . . . . . . 16

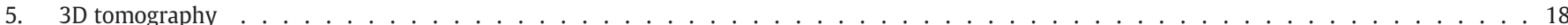

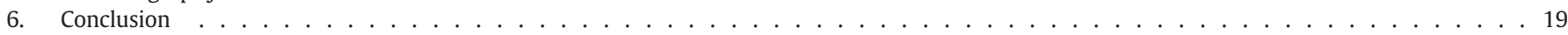

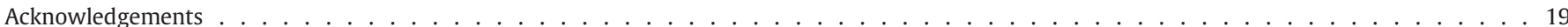

References . . . . . . . . . . . . . . . . . . . . . . . . . . . . . . . . . . . . . 20

\section{Introduction}

Many techniques are generally used for investigations of historical monuments and artworks. Ground penetrating radar (GPR) method is regularly used for non-destructive imaging (Conyers, 2004; Daniels, 2004). Numerous studies have shown that the GPR method can give good results to detect and locate fractures and discontinuities within the investigated medium (Bavusi et al., 2010; Grandjean and Goury, 1996; Pérez-Gracia et al., 2009; Rashed et al., 2003; Sambuelli et al.,

\footnotetext{
* Corresponding author at: Via archirafi, 2690123 Palermo, Italy. Tel.: + 39091 23861611.

E-mail address: patrizia.capizzi@unipa.it (P. Capizzi).
}

2011). However this method does not allow to obtain an estimate of mechanical parameters of the material and it is difficult to apply it on small artworks characterized by irregular sculpted exterior surfaces.

Also the electrical resistivity tomography (ERT) method is generally used for the study of cultural heritage (Capizzi et al., 2012; Cardarelli, 2002; Leucci et al., 2007; Nuzzo and Quarta, 2010; Tsokas et al., 2008). However, the potential field distribution within a volume delimited by a very irregular surface, such as that of a statue, is difficult to model.

Surely a technique that can be used on small objects with irregular surfaces is ultrasonic one. Ultrasonic survey for non-destructive test and for characterization of artefacts is a rather established methodology (Blitz and Simpson, 1996; Dynes and Lytle, 1979; Gambardella et 

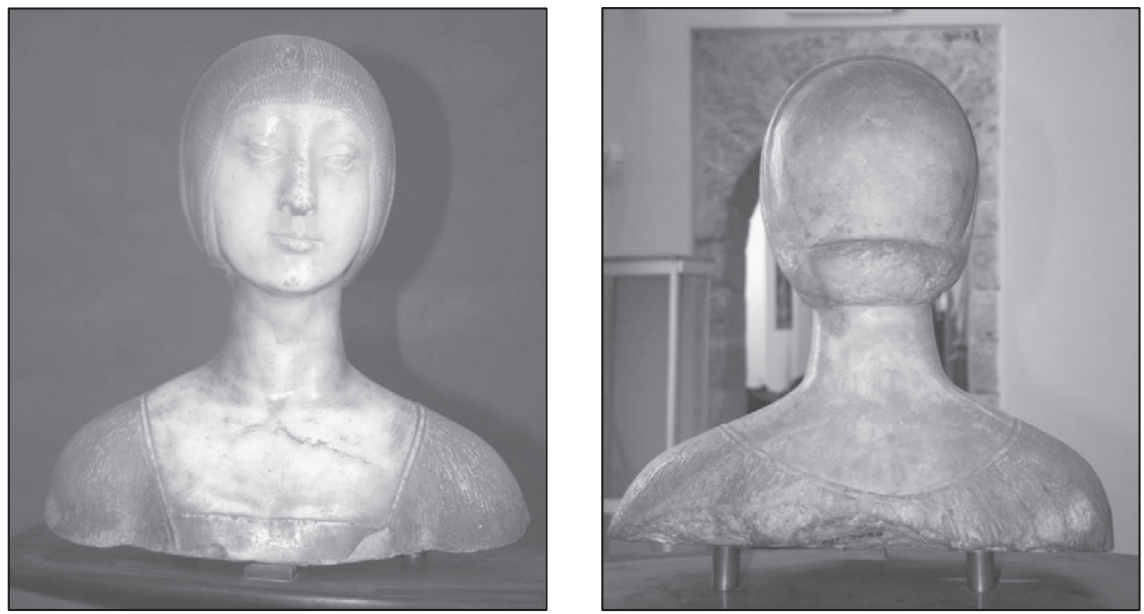

Fig. 1. Eleonora d'Aragona by Francesco Laurana (1430-1502).

al., 2008; Phillips and Fehler, 1991). 3D Ultrasonic Tomography is among the diagnostic methods for studying the structural continuity of the material, a fairly well-established technique in the diagnostic study of works of art (Capizzi et al., 2009; Cardarelli and De Nardis, 2001). This technique can be performed to evaluate either the velocity (or slowness) parameter and/or the amplitude attenuation, but the first is almost always preferred for its easiness of implementation. In any case, essential for the proper use of this diagnostic technique for the study of works of art is the careful choice of parameters used to invert experimental data. The optimization of these parameters allows locating within the studied volume possible structural unhomogeneous areas, fractures or damages.

Some tests are here presented to optimize data analysis and inversion parameters in order to better fit the shape and type of the investigated anomalies. In particular, we present the application of 3D ultrasonic tomographic technique on one of the most important statues of the Regional Gallery of Palazzo Abatellis of Palermo, the bust of Eleonora d'Aragona by F. Laurana (Fig. 1). Furthermore, the results obtained using different inversion parameters are also presented.

\section{The problem of the Eleonora d'Aragona (by F. Laurana)}

During the restoration and the expansion of the Regional Gallery of Palazzo Abatellis (Palermo, Sicily) most of the marble works of museum has been subjected to an intense analytical restoration.

The bust of Eleonora d'Aragona is a beautiful bust, shown on the original support designed by the architect Carlo Scarpa in the 60s.

The sculpture (thickness $22 \mathrm{~cm}$, width $40 \mathrm{~cm}$ and height $43 \mathrm{~cm}$ ) is finely carved from a block of white and microcrystalline marble, result of metamorphism of a limestone or dolomite. Veins are usually due to various mineral impurities such as clay, silt, sand or iron oxides which were present in the original limestone. The quarry where the block was caved is not known.

The cleanup of the sculpture has revealed the sign of a possible veining (or fracture that probably originated on a natural veining of the marble block) in the central portion of the neck, involving the whole face of the lady.

For these reasons the curators started a diagnostic study aimed not only to monitor the structural continuity of the veining or lesion, but also to detect the internal marble conditions and the precautions to be taken in view of the mobility of the bust.

\section{Ultrasonic data acquisition and analysis}

To answer to the above given questions, we decided to survey the statue using the high resolution 3D ultrasonic tomography.
Berryman (1990) suggests that it is better to use full waveform information (damping of the waves) instead of first arrival traveltimes (velocity) as input data for inversion, especially when the wavelengths are comparable in size to the anomaly dimension. In our case, considering a marble velocity of about $4600 \mathrm{~m} / \mathrm{s}$ and the central frequency of probes $(55 \mathrm{kHz})$, we obtain a wavelength of about 0.07 meter, considering the median ray length. However, in spite of the Berryman suggestion, we chose to use the acquired data sets only to implement traveltimes tomography, because in our opinion it is a very rough approximation to consider every amplitude variation due to absorption effects, especially when the coupling between transductors and marble are not fixed but changing for every ray according to the stress applied by the operator to the probes. Therefore, although amplitude information could be a valid support to interpretation of velocity analysis, the absorption (or damping) data are often affected by problems in source and receiver acoustic coupling with rough and irregular surface, like in our case.

We used the TDAS 16 instrument produced by the Italian Boviar. This multi-channel equipment acquires 16 channels using en electronic switch on four channels at a time with a maximum sampling rate of $1.25 \mathrm{MHz}$. The equipment is supplied with both receiver and transmitter probes with a central frequency of $55 \mathrm{kHz}$. Probes were equipped with special aluminium cone $(0.5 \mathrm{~cm}$ of diameter for contact area) to allow accurate positioning of the sensor on the surface.

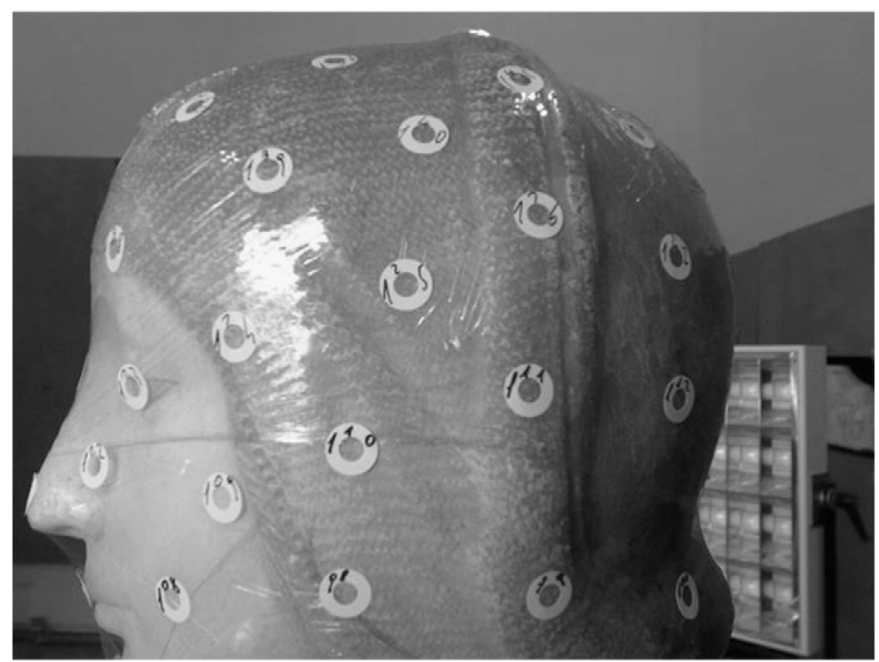

Fig. 2. Measurement points were placed on a transparent film used to avoid damages on the surface. 

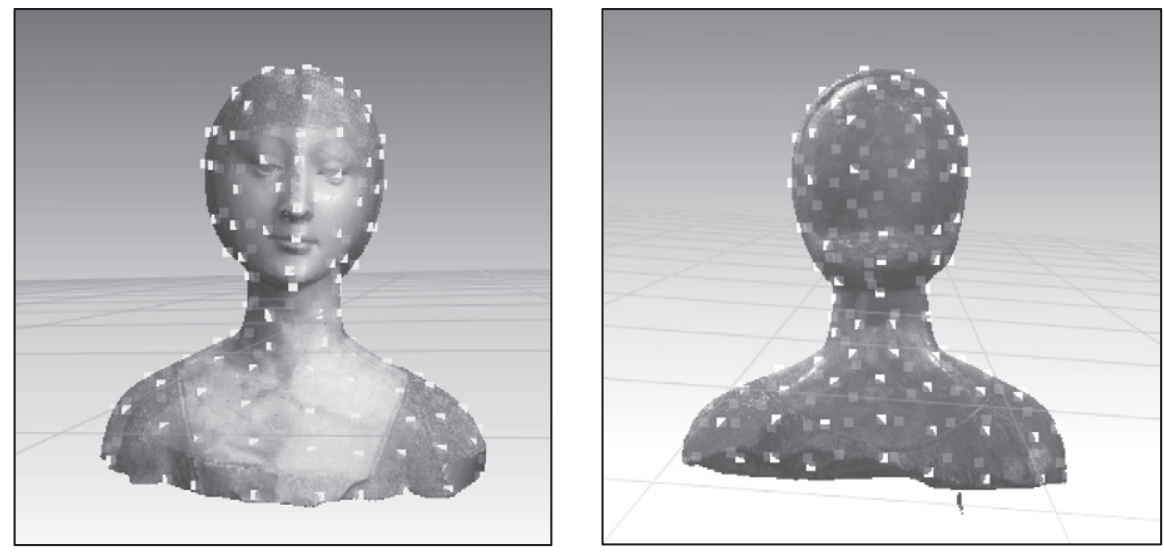

Fig. 3. The 157 measurement points used for data acquisition were located in a 3D topographic relief of the bust.

Table 1

Some acquisition parameters.

\begin{tabular}{llllll}
\hline $\begin{array}{l}\text { Number } \\
\text { of shots }\end{array}$ & $\begin{array}{l}\text { Number } \\
\text { of receiver } \\
\text { points }\end{array}$ & $\begin{array}{l}\text { Number } \\
\text { of total } \\
\text { traveltime }\end{array}$ & $\begin{array}{l}\text { Number } \\
\text { of analysed } \\
\text { traveltime }\end{array}$ & $\begin{array}{l}\text { Probe } \\
\text { frequency }\end{array}$ & $\begin{array}{l}\text { Sampling } \\
\text { frequency }\end{array}$ \\
\hline 85 & 157 & 1832 & 1768 & $55 \mathrm{kHz}$ & $1.25 \mathrm{MHz}$ \\
\hline
\end{tabular}

The surface of the art work was covered with transparent film on which were placed measurement points selected for acquisition (Fig. 2) which enabled to maintain contact with the surface probes and plasticine, used to increase the acoustic coupling between surface and probes.

A 3D topographic relief of the bust, performed with Mephisto system (produced by 4D Dynamics), was provided by Representing Department of University of Palermo to support 3D ultrasonic tomography, allowed to calculate the distances among the points used to locate the transductors and to eliminate the straight rays passing outside of the statue in the concave and convex parts.

A 3D ultrasonic tomography was obtained from 157 measurement points (Fig. 3) identified along the surface of the work was performed. The measure points were spaced from 2 to $5 \mathrm{~cm}$ and 1832 raypaths were acquired but only 1768 of these were processed. The Table 1 shows some acquisition parameters.

Traveltimes of elastic waves were measured using a manual picking procedure (Fig. 4).

Before processing, a boundary constraint was applied to tomographic data removing the straight-line velocity values lower than $2000 \mathrm{~m} / \mathrm{s}$ and higher than $6000 \mathrm{~m} / \mathrm{s}$, both being considered as outlier data. The traveltime straight ray length graph in Fig. 5 shows that all the acquired data are distributed on two different velocity trends: 3500 and $5000 \mathrm{~m} / \mathrm{s}$. Data relative to internal paths in the head of the statue, where the lesion was found, were isolated to check if they coincide with the low velocity values (Fig. 6). Fortunately, these data show high velocity values, which are evidence of good marble conditions. Further tests showed that most of the low values of velocity are associated to the paths in the frontal part of the bust (Fig. 6).

\section{Inversion tests}

Traveltime data were inverted using the commercial software package GeoTomCG, based on the tomography program 3DTOM (Jackson and Tweeton, 1996). It performs inversions with the simultaneous iterative reconstruction technique (SIRT, Peterson et al., 1985). SIRT calculations modify an initial velocity model by repeated cycles in three steps: forward computation of model travel times, calculation of residuals and application of velocity corrections to the set of voxels contained in the model. The cycle recurs through a specified number of iterations.

Some tests have been carried out to optimize inversion parameters such as voxel size and to choice between straight and curved rays.

Surely, the size and the shape of the anomalies should be considered for a correct choice of cell size for the inversion process that constrain the acquisition grid (location of transmitter and receiver probes) and the number of acquired rays. In principle, if all the investigated voxels are suitably covered by a number of rays running through, the most appropriate voxel size is that which allows a better

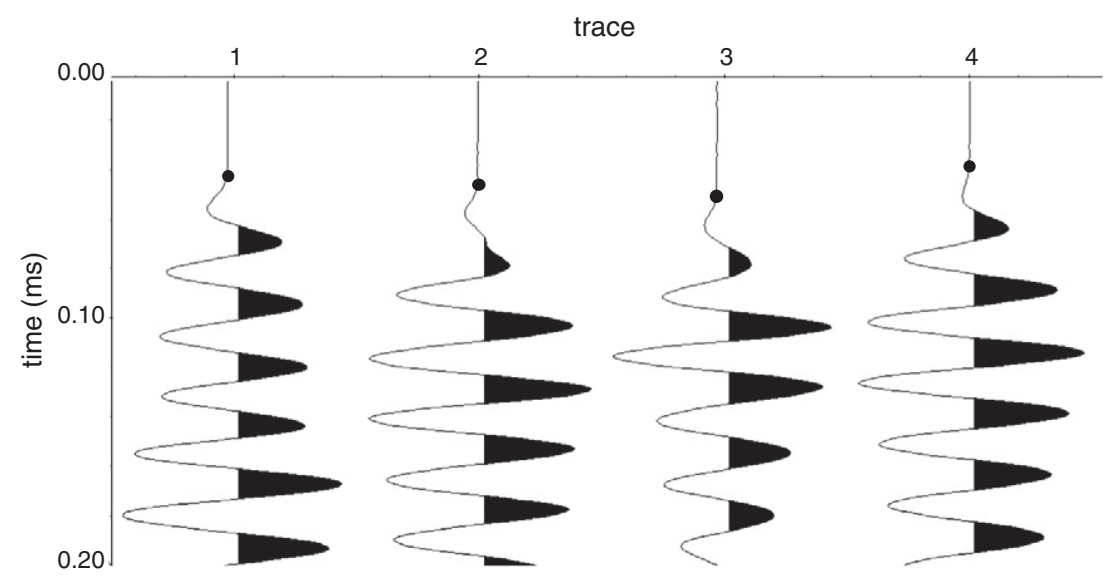

Fig. 4. Example of records with and withoutmanual picking that shows the good quality of acquired data. 


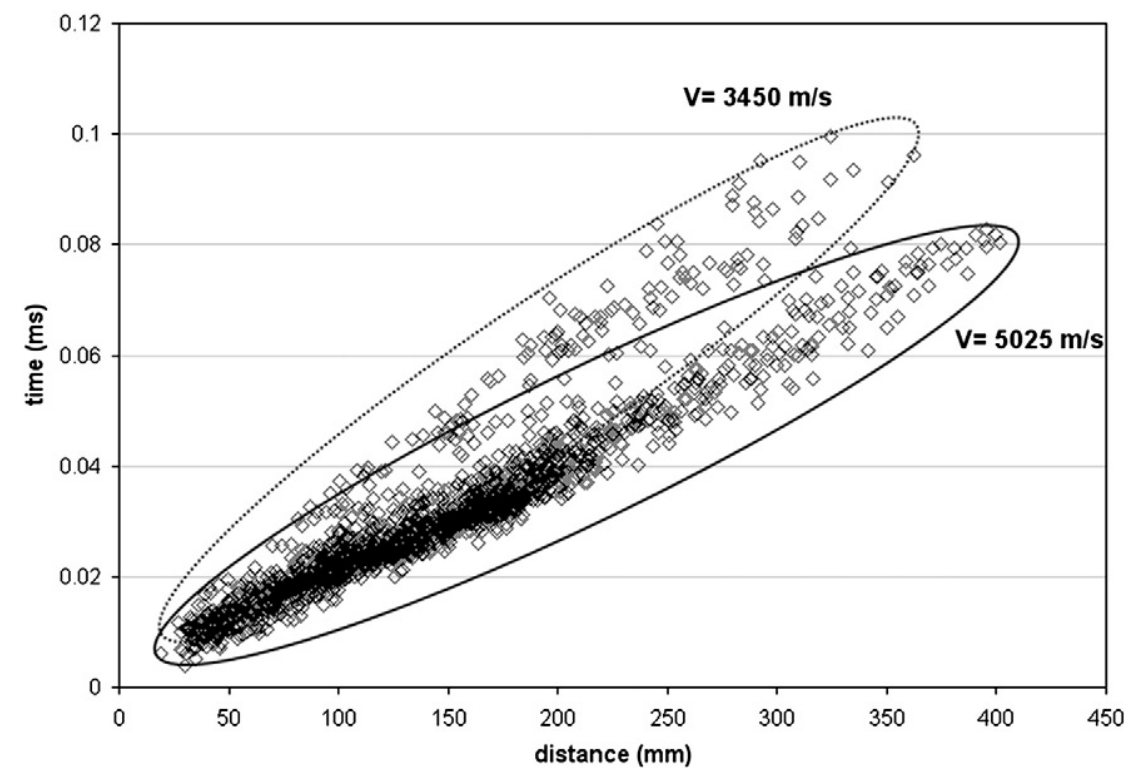

Fig. 5. Travel time graph of acquired data.

definition of the size and shapes of the anomalies contained in the artifact.

Generally investigations to identify anomalies with regular shapes allow the use of cells larger than those used in the investigations of anomalies with irregular or unknown shape.

In principle, for monochromatic waves, lateral resolution should be calculated using the theory of Fresnel radius $r$ (Cerveny and Soares, 1992), that can also be expressed as:

$r=\left[(\lambda / 4)^{2}+(L \lambda) / 2\right]^{0.5}$

$L$ being the ray length and $\lambda$ the wavelength calculated using $\lambda=v / f$, 12where $v$ is the velocity and $f$ is the frequency of the waves.

However, regarding the lateral resolution obtained by picking the first arrivals of the signals, we have to consider the maximum frequency contained in the ramp. This part of the signal contains very high frequencies (Fig. 7), much higher than the dominant one, due to the pulse modulation of the source signal. The highest frequency contained in the area of the first arrival must be extracted from the digitized signal ramp, and generally depends on the sampling frequency (Capizzi and Cosentino, 2011; Sambuelli et al., 2011), according to the well-known rule derived from the Nyquist-Shannon theorem (Grenander, 1959; Stiltz, 1961).

In Fig. 8 the lateral resolution, calculated using the frequency of the probes and the Nyquist frequency $(1.25 / 2 \mathrm{MHz})$ versus the ray lengths are plotted. Considering the lateral resolution calculated for the Nyquist frequency and the median ray length $(0.118 \mathrm{~m})$, the voxel size should be set to $2 \mathrm{~cm}$.

Fig. 9 shows the results for a horizontal 2D section obtained using different voxel size for inversion process. The 2D sections are extracted at the bottom of the 3D model, obtained using all 1832 paths. It's clear that using a big voxel size $(4 \mathrm{~cm})$ the shape of anomalies are too smoothed, whereas the use of a voxel size too small $(0.5 \mathrm{~cm})$ highlighted anomalous rays. This comparison has been repeated for different 2D sections and finally the voxel size has been set to $2 \mathrm{~cm}$. Probably it is below the real resolution and cause a too large number of cells, some of which are characterized by an "anomalous value" of velocity. For

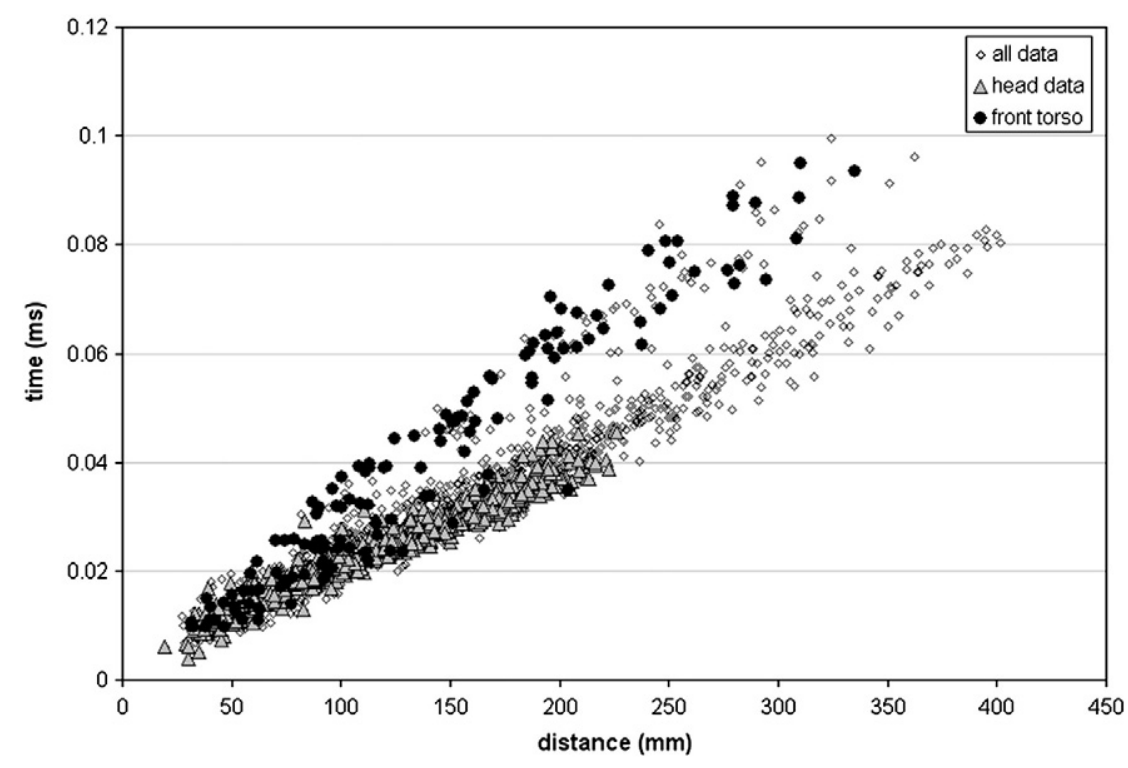

Fig. 6. Travel time graph of acquired data, where data relative to head and front torso have been isolated. 


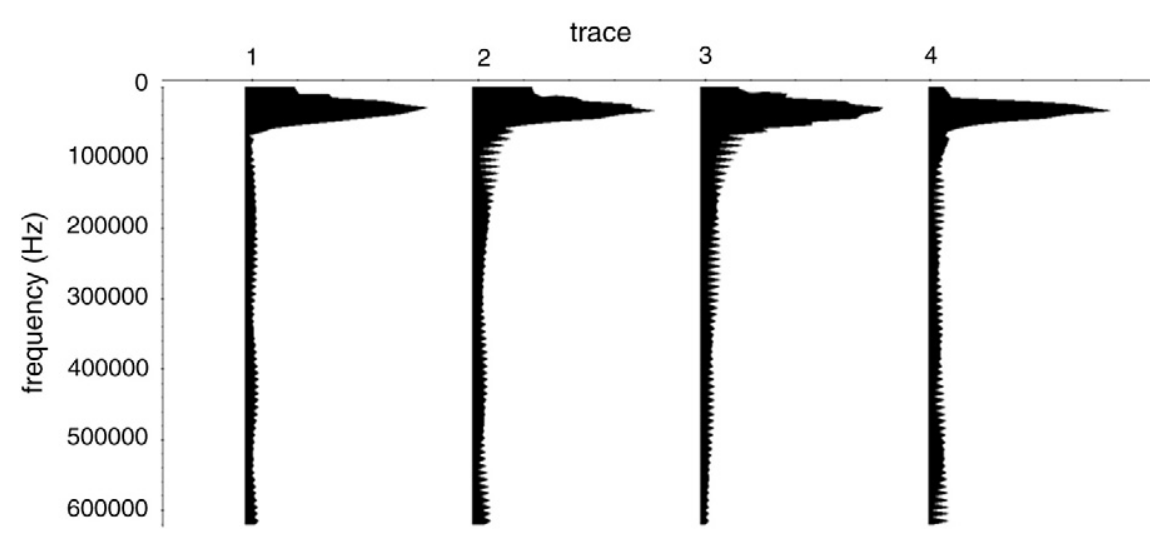

Fig. 7. Spectra of the traces showed in Fig. 4. Higher frequencies than the dominant one are present.

these reasons, an upper and lower bounds on calculated velocities and a regularization to the average velocity were applied to reduce the velocity variation. The velocity bounds were applied based on a general knowledge of rock type: $2000 \mathrm{~m} / \mathrm{s}$ and $6000 \mathrm{~m} / \mathrm{s}$ respectively as lower and upper bounds. A regularization to the average velocity (Santamarina and Fratta, 1998) were used to decrease the node-to-node variation in the velocity. The average velocity, in the first iteration, is the average straight-line velocity of all raypaths and, for subsequent iterations, the average node velocity for all nodes that are affected by each raypath. Nodes for zones without raypaths are not considered.

The strength of the regularization coefficient (also called damping) can be chosen. Regularization started with a small coefficient, 0.01, then gradually increased it (step of 0.01 ) to determine the effect on the residuals. Increasing the value of the damping coefficient increases the effect of the average velocity and decreases the node-to-node variation in the velocity, but a too large coefficient will force too much uniformity and will hide important velocity anomalies. For this reason and considering the goodness of the data, the maximum value of damping applied was 0.1 .

Ray tracing and travel-time computation may be performed with either straight or curved raypaths. As stated by the Fermat principle, energy travels along the fastest path, so that a fast anomaly attracts energy where a slow anomaly rejects energy. This behaviour cannot be considered when we use straight rays. The effect on the inversion is that fast anomalies are over-dimensioned, while slow anomalies are reduced in size or even undetected. Then, for a more accurate estimation of the anomaly dimensions, a curved ray inversion is necessary. GeoTomCG software, used for data inversion, performs curved ray tracing with a revised form of ray bending, derived from the method given by Um and Thurber (1987).

A comparison between a tomography performed using straight and curved rays is shown in Fig. 10. The other parameters of inversion have not been changed.

Although the use of curved beams describes sometimes a too strong simplification compared to the true distribution of the rays inside investigated volume, the curved-ray tomography shows better results than the tomography obtained considering the straight-ray approximation. Apparently the choice between straight and curved rays should be done case by case, considering the size and shape of the expected anomalies.

\section{3D tomography}

A tomographic model were calculated, using elementary cells of size $2 \times 2 \times 2 \mathrm{~cm}$, optimized for the size of the anomalies investigated, for a total of 4750 cells. 1832 data were inverted simultaneously. The model obtained shows quite homogeneous velocity values for the marble bust with an average speed of about $4600 \mathrm{~m} / \mathrm{s}$, and does not highlight anomalies located in the area of the assumed internal fracture. Considering this final model, the median misfit calculated as percentage difference between measured traveltimes and calculated traveltimes was $10 \%$. This is a good result considering the irregular shape of the volume under investigation and the resulting numerous phenomena of diffraction and reflection which are not considered in the model.

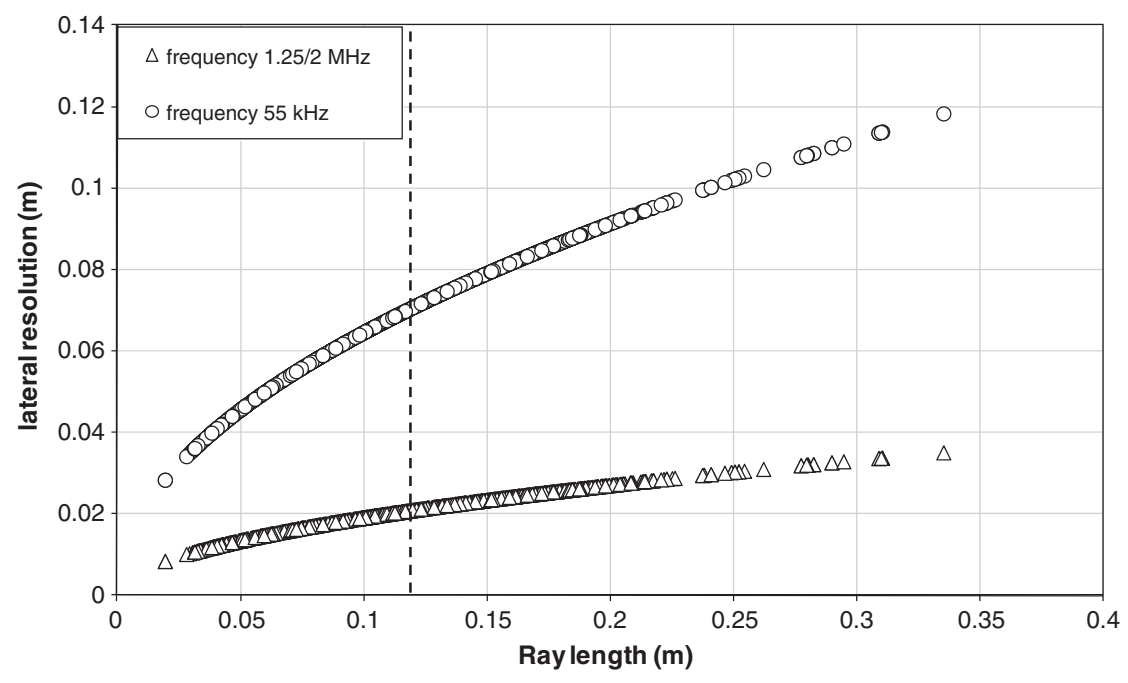

Fig. 8. Plot of the lateral resolution versus ray lengths in a material with a velocity of $4600 \mathrm{~m} / \mathrm{s}$. The median ray length is $0.118 \mathrm{~m}$. 


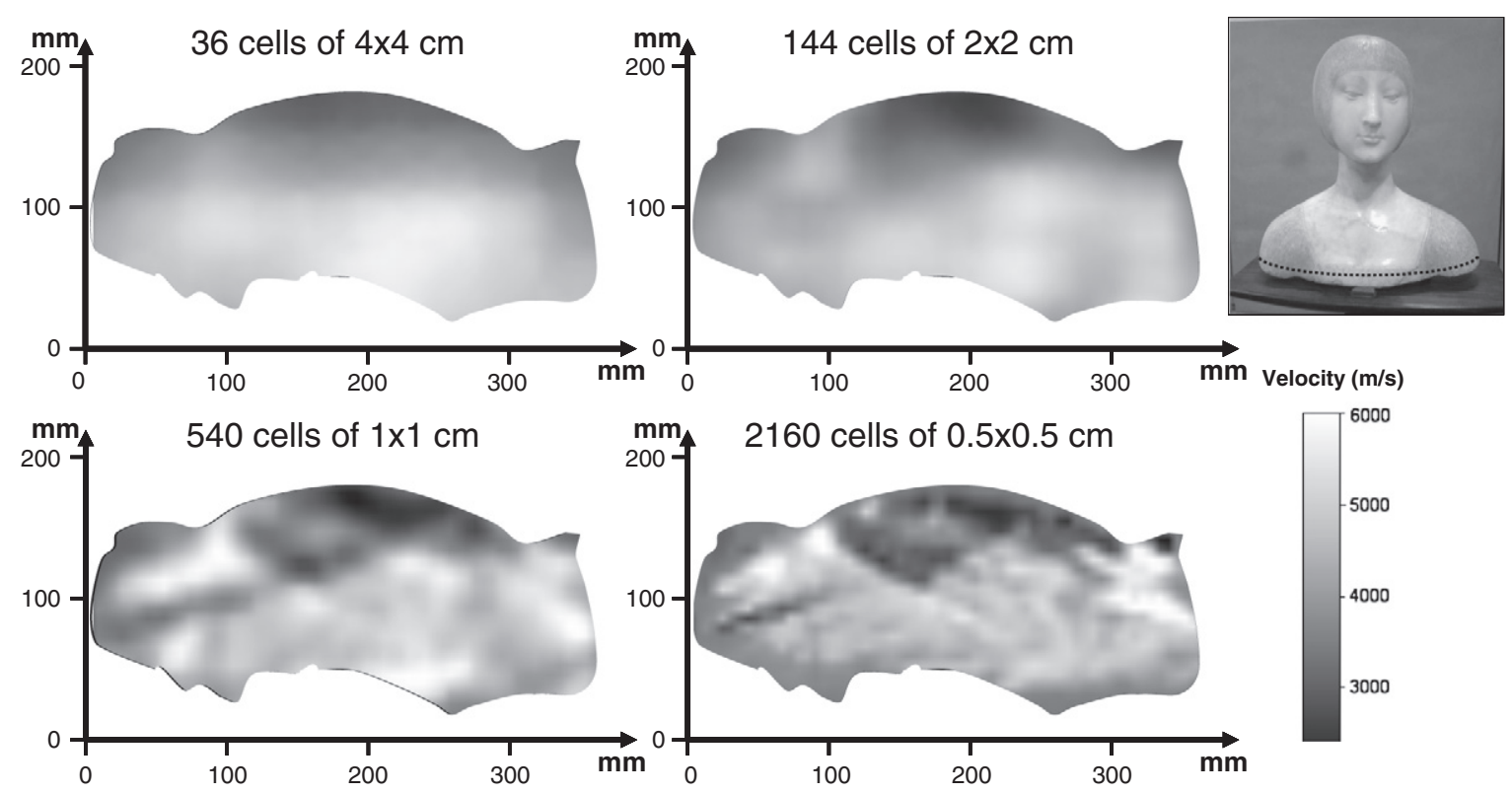

Fig. 9. Inversion results obtained for the same 2D section, using different cell dimension. In the picture the trace of the 2D section is shown.

A 3D representation with a $3300 \mathrm{~m} / \mathrm{s}$ isosurface is shown in Fig. 11. Luckily, the model does not show significant anomalies at the lesion on the face of the lady. Also the upper torso (head and neck) shows velocity values corresponding to a sufficiently homogeneous and well-preserved marble. However, the velocity model shows low values in the lower front portion of the trunk at the breasts, according to the traveltime graph analysis (Fig. 12). In fact, the original pedestal designed by Carlo Scarpa makes this area bears the entire weight of the statue.

\section{Conclusion}

An ultrasonic investigation was performed on the statue of Eleonora d'Aragona by F. Laurana (1430-1502) and the data were used to perform some tests on the importance of the choice of the main inversion parameters.

A comparison between inversion models obtained using different voxel size was done. We choose to use a cell size lower than expected resolution and a large number of cells. This obviously caused some instability in the inversion process and we needed to apply some grid constrains as stabilizers.
Obviously the expected resolution has to be considered, but probably the real resolution is higher than that calculated using the central frequency of probes, due to the multi-frequency nature of the pulsed signal.

Also the choice between straight rays and curved rays must be taken with care, considering that the distribution of rays within the investigated volume is always a simplification of the real behaviour of the paths of the elastic waves in the material. In our case curved rays showed better results than straight rays, but the choice between straight and curved rays should be done considering the size and shape of the expected anomalies.

The obtained model shows velocity values corresponding to a sufficiently homogeneous and well-preserved marble. However, the velocity model shows low values in the lower front portion of the trunk at the breasts, according to the traveltime graph analysis.

\section{Acknowledgements}

The authors thank Mrs. Giulia Davì, director of the Regional Gallery of Palazzo Abatellis (Palermo, Sicily), Mr. Guido Meli and Mrs Lorella Pellegrino, respectively director and restorer of the Sicilian Regional
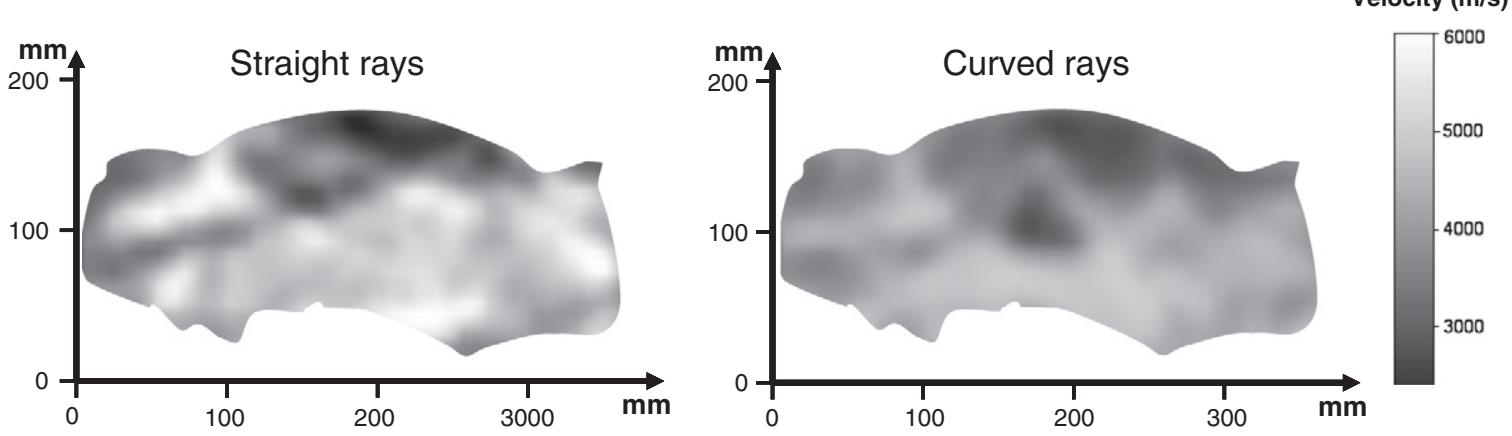

Fig. 10. Inversion results obtained for the same 2D section (Fig. 7), using straight and curved rays. 


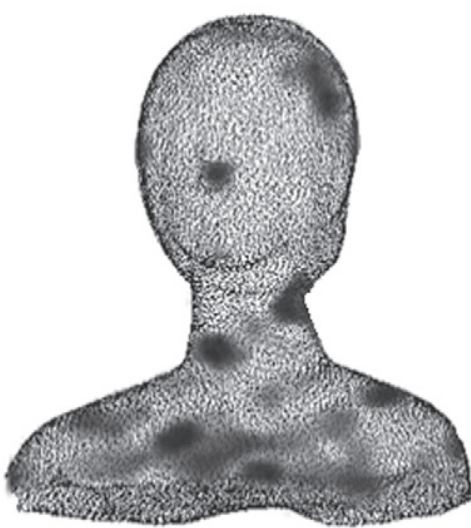

back

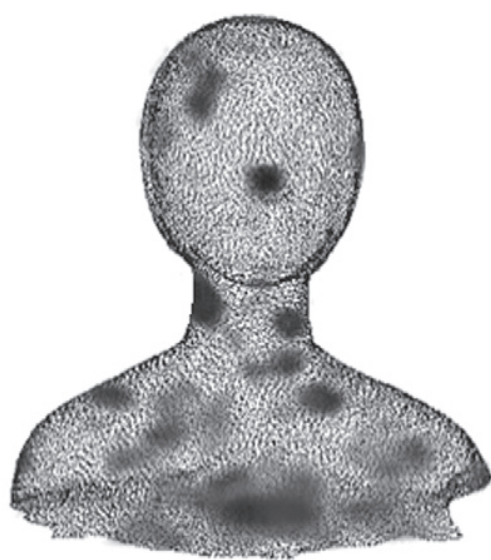

Front

Fig. 11. 3D rendering of the investigated volume. Black areas indicate zones with a velocity lower than $3300 \mathrm{~m} / \mathrm{s}$.
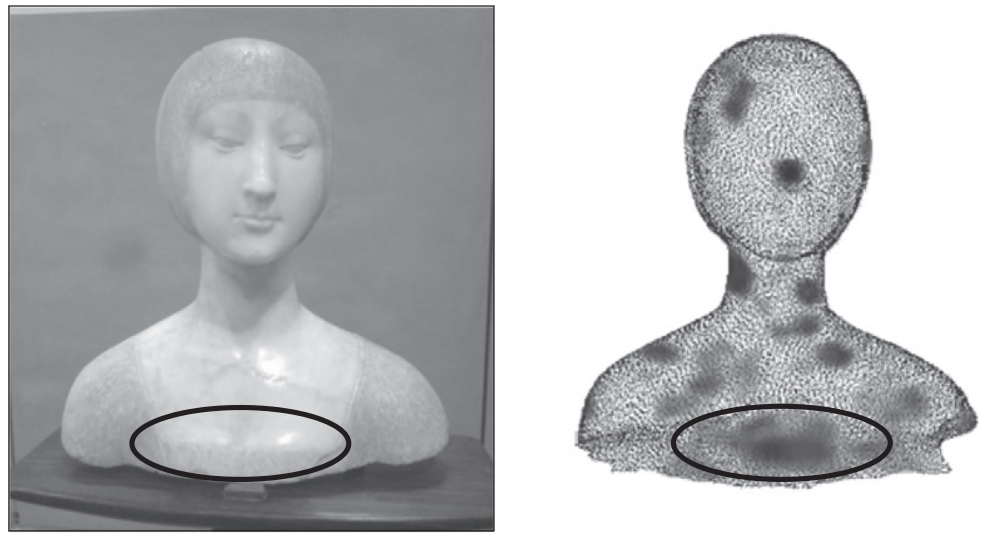

Velocity $(\mathrm{m} / \mathrm{s})$

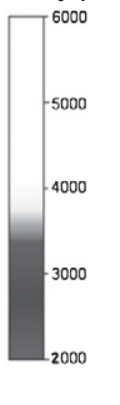

Fig. 12. Frontal 3D image with trasparency of the investigated volume (right) showing an area with low velocity, corresponding to the support point of the bust.

Centre for Conservation and Restoration, for their availability and indispensable cooperation.

\section{References}

Bavusi, M., Soldovieri, F., Piscitelli, S., Loperte, A., Vallianatos, F., Soupios, P., 2010. Ground-penetrating radar and microwave tomography to evaluate the crack and joint geometry in historical buildings: some examples from Chania, Crete, Greece. Near Surface Geophysics 8, 377-387.

Berryman, J.G., 1990. Stable iterative reconstruction algorithm for nonlinear traveltime tomography. Inverse Problems 6, 21-42.

Blitz, J., Simpson, G., 1996. Ultrasonic Methods of Non-destructive Testing. Series: NonDestructive EvaluationSpringer.

Capizzi, P., Cosentino, P., 2011. Electromagnetic and ultrasonic investigations on roman marble slab. Journal of Geophysics and Engineering 8, S117-S125.

Capizzi, P., Cosentino, P.L., Martorana, R., Razo Amoroz, I., Riela, S., Rizzari, G., Schiavone, S. 2009. Indagini geofisiche a supporto dell'intervento di restauro di Palazzo Branciforte (Palermo). Lo Stato dell'Arte 7 - VII IGIIC, 7, pp. 121-128.

Capizzi, P., Martorana, R., Messina, P., Cosentino, P.L., 2012. Geophysical and geotechnical investigations to support the restoration project of the Roman 'Villa del Casale'. Piazza Armerina, Sicily, Italy. Near Surface Geophysics 10, 145-160.

Cardarelli, E., 2002. Geoelectric survey by ERT to investigate marble ruins at the Roman Forum, Rome, Italy. European Journal of Environmental and Engineering Geophysics 7, 219-228.

Cardarelli, E., De Nardis, R., 2001. Sesmic refraction, isotropic anisotropic seismic tomography on an ancient monument (Antonino e Faustina temple AD 141). Geophysical Prospecting 49, 228-240.

Cerveny, V., Soares, J.E.P., 1992. Fresnel volume ray tracing. Geophysics 57, 902-915.

Conyers, L.B., 2004. Ground-Penetrating Radar for Archaeology. AltaMira Press, Walnut Creek, CA, p. 224.

Daniels, D.J., 2004. Ground Penetrating Radar, 2nd edn. Institution of Electrical Engineers IEE Press, p. 726.

Dynes, K.A., Lytle, R.J., 1979. Computerized geophysical tomography. Proceedings of the IEEE 67, 1065-1073.

Gambardella, S., Danesi, A., Cosentino, P.L., Capizzi, P.., Fiandaca, G., 2008. L'indagine sonica ed ultrasonica come prassi necessaria alla conoscenza di strutture complesse. Il rimontaggio di una statua di epoca romana da Locri: un caso esemplare. Lo Stato dell'Arte VII, 689-694.

Grandjean, G., Goury, J.C., 1996. GPR data processing for 3D fracture mapping in a marble quarry (Thallos, Greece). Journal of Applied Geophysics 36, 19-30.

Grenander, U., 1959. Probability and Statistics. Harald Cramé Volume.Almqvist, Stockholm.

Jackson, M.J., Tweeton, D.R., 1996. 3DTOM: Three-Dimensional Geophysical Tomography. USBM RI 9617.

Leucci, G., Cataldo, R., De Nunzio, G., 2007. Assessment of fractures in some columns inside the crypt of the Cattedrale di Otranto using integrated geophysical methods. Journal of Archaeological Science 34, 222-232.

Nuzzo, L.A.N.D., Quarta, T., 2010. Near-surface geophysical investigations inside the cloister of the historical palace 'Palazzo dei Celestini' in Lecce, Italy. Journal of Geophysics and Engineering 7, 200-210.

Pérez-Gracia, V. Caselles, O. Clap’es, J. Osorio, R Canas, J.A. Pujades, L.G. 2009. Radar exploration applied to historical buildings: a case study of the Marques de Llio Palace, in Barcelona (Spain). Engineering Failure Analysis 16, 1039-1050.

Peterson, J.E., Paulson, B.N.P., McEvilly, T.V., 1985. Applications of algebraic reconstruction techniques to crosshole seismic data. Geophysics 50, 1566-1580.

Phillips, W.S., Fehler, M.C., 1991. Traveltime tomography: a comparison of popular methods. Geophysics 56, 1639-1649.

Rashed, M., Kawamura, D., Nemoto, H., Miyata, T., Nakagawa, K., 2003. Ground penetrating radar investigations across the Uemachi fault, Japan. Journal of Applied Geophysics 53, 63-75.

Sambuelli, L., Bohm, G., Capizzi, P., Cardarelli, E., Cosentino, P., 2011. Comparison among GPR measurements and ultrasonic tomographies with different inversion algorithms: an application to the basement of an ancient Egyptian sculpture. Journal of Geophysics and Engineering 8, S106-S111.

Santamarina, JC Fratta, D 1998. Introduction to Discrete Signals and Inverse Problems in Civil Engineering. ASCE Press, Reston, VA.

Stiltz, H.L., 1961. Aerospace Telemetry. Prentice-Hall, Englewood Cliffs, NJ.

Tsokas, G.N., Tsourlos, P.I., Vargemezis, G., Novack, M., 2008. Non-destructive electrical resistivity tomography for indoor investigation: the case of Kapnikarea Church in Athens. Archaeological Prospection 15, 47-61.

Um, J., Thurber, C., 1987. A fast algorithm for two-point seismic ray tracing. Bulletin of the Seismological Society of America 77, 972-986. 